\title{
Demonstration of microchimerism in pregnant sows and effects of congenital PRRSV infection
}

\author{
Uladzimir U Karniychuk"1*, Wander Van Breedam', Nadine Van Roy ${ }^{2}$, Claire Rogel-Gaillard ${ }^{3}$ and Hans J Nauwynck
}

\begin{abstract}
The presence of foreign cells within the tissue/circulation of an individual is described as microchimerism. The main purpose of the present investigation was to study if microchimerism occurs in healthy sows/fetuses and if porcine reproductive and respiratory syndrome virus (PRRSV) infection influences this phenomenon. Six dams were inoculated intranasally with PRRSV and three non-inoculated dams served as controls. Male DNA was detected in female fetal sera of all dams via PCR. Male DNA was also detected in the maternal circulation. Sex-typing FISH showed the presence of male cells in the female fetal organs and vice versa. PRRSV infection did not influence microchimerism, but might misuse maternal and sibling microchimeric cells to enter fetuses.
\end{abstract}

\section{Introduction, methods and results}

The presence of small numbers of foreign cells within tissues or circulation of an individual is described as microchimerism [1]. Naturally acquired microchimerism refers to sibling (exchange of fetal cells in between siblings), maternal (presence of maternal cells within fetus) and fetal microchimerism (presence of fetal cells within mother) [2-16]. Fetal and maternal cell exchange is common in human and rodent pregnancy [1]. Both fetal and maternal microchimerism has been associated with different autoimmune disorders, pregnancy pathology and transplantation complications [1,17-19]. Otherwise, fetal cell differentiation in maternal tissues is presumably involved in tissue repair and protection against cancer [1]. Microchimerism may also play an important role in the physiology and pathology of pregnancy. However, at present no information is available on this phenomenon in swine.

Porcine reproductive and respiratory syndrome virus (PRRSV) is the cause of severe reproductive problems in sows [20]. The means by which PRRSV crosses the placental barrier remain unknown. Prior to fetal infection, PRRSV replicates in the endometrium and shows a very restricted tropism for $\mathrm{Sn}+/ \mathrm{CD} 163+$ macrophages $[21,22]$. Therefore, PRRSV might use susceptible cells as a vehicle to cross the uterine epithelium/trophoblast

\footnotetext{
* Correspondence: uladzimir.karniychuk@UGent.be

'Laboratory of Virology, Faculty of Veterinary Medicine, Ghent University, Ghent, Belgium

Full list of author information is available at the end of the article
}

layers. Some pathological conditions during pregnancy, especially diseases that affect the placental environment, might influence fetal and maternal cell exchange. For instance, it has been observed that a mild inflammation caused by Pertussis toxin enhances cell migration through the murine placenta [23]. During replication in the endometrium, PRRSV causes apoptosis of infected and surrounding cells [22] and changes the expression of cellular receptors (increased Sn expression and change in the MHC class I and II expression) (not published results). Potentially, PRRSV-mediated changes in endometrial macrophages and/or in uterine epithelial/ trophoblast layers may trigger events which influence the cell transmigration process. If a physiological cell exchange between mother and fetuses occurs in swine, it is interesting to examine if PRRSV infection influences it. By facilitating transplacental cell migration, PRRSV infection may favor cell-mediated PRRSV transfer from mother to fetuses. In contrast, PRRSV-mediated changes in maternal tissues may also inhibit transmigration processes, resulting in the protection of fetuses. Therefore, the main purpose of the present investigation was to study if microchimerism occurs in healthy sows/fetuses and if PRRSV infection influences this phenomenon.

Nine dams from a PRRSV-free herd were kept in isolation rooms. The experimental design is summarized in Table 1. Six dams were inoculated intranasally with $10^{5}$ TCID $_{50}$ type 1 PRRSV 07 V063 (GenBank No: GU737264) at $70\left(\right.$ dam $\left.\mathrm{I}_{70}\right)$ or $90\left(\mathrm{I}_{90^{-}}-1, \mathrm{I}_{90^{-}}-2, \mathrm{I}_{90^{-}}-3, \mathrm{I}_{90^{-}}\right.$ $4, \mathrm{I}_{90}-5$ ) days of gestation in $4 \mathrm{~mL}$ of phosphate buffered
C Biomed Central

(c) 2012 Karniychuk et al; licensee BioMed Central Ltd. This is an Open Access article distributed under the terms of the Creative Commons Attribution License (http://creativecommons.org/licenses/by/2.0), which permits unrestricted use, distribution, and reproduction in any medium, provided the original work is properly cited. 
Table 1 Experimental design.

\begin{tabular}{|c|c|c|c|c|c|c|}
\hline \multirow[t]{2}{*}{ Dam } & \multirow[t]{2}{*}{ Parity } & \multirow[t]{2}{*}{ PRRSV inoculation at... gd $^{+}$} & \multirow[t]{2}{*}{ Euthanized at... gd } & \multicolumn{3}{|c|}{ Number of fetuses } \\
\hline & & & & Total & Female & Male \\
\hline$I_{70}$ & 4 & 70 & 80 & 11 & 7 & 4 \\
\hline$l_{90^{-1}}$ & 5 & 90 & 100 & 14 & 9 & 5 \\
\hline $1_{90}-2$ & 1 & 90 & 100 & 14 & 5 & 9 \\
\hline $1_{90}-3$ & 1 & 90 & 100 & 17 & 9 & 8 \\
\hline $1_{90}-4$ & 1 & 90 & 110 & $12^{*}$ & 8 & 2 \\
\hline $1_{90}-5$ & 1 & 90 & 110 & $16^{*}$ & 9 & 6 \\
\hline Con-1 & 1 & - & 100 & 13 & 7 & 6 \\
\hline Con-2 & 10 & - & 100 & 16 & 11 & 5 \\
\hline Con-3 & 6 & - & 100 & 15 & 7 & 8 \\
\hline
\end{tabular}

${ }^{\dagger} \mathrm{gd}$ : gestation day; -: not inoculated. *Due to mummification, the gender determination in two and one fetus from dams $\mathrm{I}_{90^{-}} 4$ and $\mathrm{l}_{90}-5$, respectively, was not possible.

saline (PBS) (2 mL in each nostril). Three non-inoculated dams were included in the study (Table 1). Blood was collected from all dams before and after PRRSV inoculation. The control animals were euthanized at 100 days of gestation. PRRSV-inoculated dams were euthanized at 10 days post-inoculation $\left(\mathrm{I}_{70}, \mathrm{I}_{90}-1, \mathrm{I}_{90}-2, \mathrm{I}_{90}-3\right)$ or at 20 days post-inoculation $\left(\mathrm{I}_{90}-4, \mathrm{I}_{90}-5\right)$ and uteri were removed. The uterine wall adjacent to every fetus was incised and fetal blood was collected from the umbilical cords. Blood was collected with individual disposable syringes and gloves were changed prior to every sampling. The gender of individual fetuses was recorded and lungs and liver of each fetus were collected and snap frozen. To confirm PRRSV infection, virus isolation and titration from maternal and fetal sera and PRRSVspecific immunofluorescence (IF) staining on frozen tissue sections were performed [22,24].

DNA was isolated from sera $(200 \mu \mathrm{L})$ of fetuses and dams using a QIAmp DNA Blood Mini Kit (Qiagen, USA). The final volume of DNA solution after each extraction was $50 \mu \mathrm{L}$. A real time PCR assay was set up in a volume of $30 \mu \mathrm{L}$. The following components were added to a PCR tube: $15 \mu \mathrm{L}$ of $2 \times$ SensiMix ${ }^{\mathrm{TM}}$ Probe Master mix (Bioline, UK), $1.25 \mu \mathrm{L}$ sense primer $(420$ $\mathrm{nM}), 1.25 \mu \mathrm{L}$ antisense primer $(420 \mathrm{nM}), 0.625 \mu \mathrm{L}$ Universal ProbeLibrary Probe \# 162 (210 nM) (Roche, USA) and water to make up a total volume of $25 \mu \mathrm{l}$. Finally, 5 $\mu \mathrm{L}$ of the extracted serum DNA was added. Primers (sense 5-tcaaacgatggacgtgaaac-3; antisense 5ttcatgggtcgcttgacac-3; $71 \mathrm{bp}$ ) and a probe specific for a porcine male sex-determining region Y (SRY) were generated with Probe Finder software (Roche, USA). As an amplification control, we used a PCR specific for porcine zinc finger $\mathrm{X}$-chromosomal gene (ZFX), which is present in both male and female samples. Primers (sense 5-tgagttggtttgtgaacatgaat-3; antisense 5-ccttacagtgtactggtatttcaga-3; $91 \mathrm{bp}$ ) and probe \#114 specific to ZFX were generated with Probe Finder software (Roche,
USA). The ZFX PCR protocol was identical to the SRY PCR protocol; only $2 \mu \mathrm{L}$ (700 $\mathrm{nM}$ ) of each primer was used. The real time PCR was performed using a StepOne $^{\text {TM }}$ Real-Time PCR system (AppliedBiosystems, USA). Identical thermal profiles were used for both the SRY and the ZFX reactions: denaturation for $15 \mathrm{~min}$ at $95^{\circ} \mathrm{C}$, followed by 45 cycles of $95^{\circ} \mathrm{C}$ for $15 \mathrm{~s}$ (denaturation) and $60^{\circ} \mathrm{C}$ for $1 \mathrm{~min}$ (annealing and elongation).

For PCR validation, DNA from randomly selected male and female fetal sera was tested with SRY and ZFX PCRs. Afterwards, PCR products were subjected to gel electrophoresis to ensure the correct size of the amplicons (Additional file 1). The specificity of the SRY PCR was validated by testing genomic DNA extracted from male or female swine ear skin; only porcine male DNA was amplifiable (Additional file 1).

Following validation of PCR analyses, female fetal and dam samples were analyzed. Each sample was analyzed in five and two-three replicates for SRY and ZFX, respectively, in the same plate. Positive and negative controls (DNA extracted from male sera and multiple negative water blanks, respectively) were included in every PCR run. Fluorescence data calculated by the Step-One ${ }^{\mathrm{TM}}$ Real-Time PCR system were collected for each well and a sample was considered positive for SRY or ZFX when there was an exponential increase in fluorescence during the PCR amplification. Randomly selected samples were also subjected to gel electrophoresis during the experiment, to ensure the correct size of the amplicons.

Strict precautions were taken to prevent PCR contamination. Separate DNA isolation kits were used for female and male samples. DNA extractions and set up of PCR assays were performed under ultraviolet (UV) light-equipped safety hoods, with UV run for $1 \mathrm{~h}$ between experiments. Aerosol-resistant pipette tips and disposable gloves were always used. Reagent controls, with water instead of serum were included in every 
DNA isolation run. Controls were consistently negative in all experiments. Isolation of DNA, setup of PCR reactions, PCR assays and gel electrophoresis of PCR products were performed in separate locations.

A probe mapping to the porcine $\mathrm{Y}$ chromosome (BAC clone 428D8; SSCYp1.2 chromosome location) and a probe mapping to the porcine $\mathrm{X}$ chromosome (BAC clone 223 G10; SSCXq2. chromosome location) were used in sex-typing fluorescence in situ hybridization (FISH) [25-27]. Liver and lungs of five randomly selected male and five female fetuses from all dams were subjected to FISH analysis. From the $\mathrm{I}_{70}$ dam, liver and lungs of three and five randomly selected male and female fetuses, respectively, were subjected to FISH analysis. Three 5-7 $\mu$ m-thick cryosections were made from each sample. These sections were cut $100 \mu \mathrm{m}$ apart from each other in the tissue block. All sections were examined using a Zeiss Axioplan 2 fluorescence microscope (in 50 fields, $100 \times$ objective for a total magnification of $\times 1000$ ).

All data for statistical analyses were obtained only from dams euthanized at 100 days of gestation (Table 1). PRRSV-inoculated dams, which were euthanized at 80 and 110 days of gestation, were excluded from statistical analyses because the gestation stage influences transplacental cell exchange [1]. All statistical tests were performed with the SigmaPlot11 software. A 95\% confidence interval $(p<0.05)$ was applied for the statistical significance.

All non-inoculated dams and their fetuses remained PRRSV-negative throughout the entire experiment. All inoculated dams became viremic $\left(10^{2.3-4.8} \mathrm{TCID}_{50} / \mathrm{mL}\right)$ and transplacental infection occurred in the five dams inoculated with PRRSV at 90 days of gestation (Table 2 ). Twelve to one hundred percent of the fetuses from these dams were viremic with titres ranging between $10^{2.2}-10^{7.3} \mathrm{TCID}_{50} / \mathrm{mL}$ (Additional file 2 and 3 ). Viruspositive cells were observed in the internal organs of viremic fetuses by PRRSV-specific IF staining. In contrast, dam $\mathrm{I}_{70}$, inoculated at 70 days of gestation, was viremic $\left(10^{2.3} \mathrm{TCID}_{50} / \mathrm{mL}\right)$, but no viremia or PRRSVpositive cells were detected in her fetuses.

A PCR assay to determine the gender of pigs has been previously described [28]. However, this test amplifies human DNA too, which increases the chance of falsepositive results due to contamination during processing the samples. In the present study, probe-based PCR assays that specifically detect porcine SRY and ZFX were designed.

In total, 66 sera from female fetuses were tested in the SRY and ZFX PCRs. The results are summarized in Figure 1 and Additional file 2. SRY was detected in female fetal sera from both non-inoculated and PRRSV-inoculated dams. Non-inoculated and PRRSV-inoculated dams, had $20-43 \%$ and $20-100 \%$ of SRY-positive female fetuses, respectively. Male DNA was also detected in the maternal circulation of pregnant dams before and after infection (Table 2). All female fetal and maternal samples were amplifiable by the ZFX assay.

Microchimeric cells were detected via FISH in organs of fetuses from all nine dams (Figure 1, Additional file 2 and 3). Non-inoculated dams and dams with congenital PRRSV infection had $40-80 \%$ and $0-80 \%$ of female fetuses with male microchimeric cells and $80-100 \%$ and $0-100 \%$ of male fetuses with female microchimeric cells, respectively. In both cases, the number of fetuses which homed foreign cells did not differ significantly between the two dam groups ( $p>0.05$, tested with the Chisquare test and Fisher exact test, Additional file 4). Transplacental infection did not also influence the number of microchimeric cells within fetuses of both genders $(p>0.05$, tested with the Mann-Whitney rank sum test).

Male (XY) cells were detected in 12 out of 30 tested female fetuses; 25 out of 30 male fetuses harbored female cells $(p<0.05$, tested with the Chi-square test,

Table 2 Results of PRRSV titration, SRY and ZFX PCR in dam sera.

\begin{tabular}{|c|c|c|c|c|c|c|}
\hline \multirow[t]{2}{*}{ Dam } & \multicolumn{2}{|c|}{ PRRSV titre $\log 10 \mathrm{TCID}_{50} / \mathrm{ml}$ of sera at the day of... } & \multicolumn{2}{|c|}{ SRY PCR results at the day of... } & \multicolumn{2}{|c|}{ ZFX PCR results at the day of } \\
\hline & inoculation & euthanasia & inoculation & euthanasia & inoculation & euthanasia \\
\hline$\overline{I_{70}}$ & - & 2.3 & + & - & + & + \\
\hline $1_{90^{-1}}$ & - & 4.8 & - & + & + & + \\
\hline $1_{90}-2$ & - & 3.3 & - & + & + & + \\
\hline $1_{90}-3$ & - & 3.3 & - & - & + & + \\
\hline $1_{90}-4$ & - & 2.3 & - & - & + & + \\
\hline $190^{-5^{+}}$ & - & - & + & + & + & + \\
\hline Con-1 & - & - & - & - & + & + \\
\hline Con-2 & - & - & - & - & + & + \\
\hline Con-3 & - & - & - & - & + & + \\
\hline
\end{tabular}

PRRSV titres < 1.0 (detection limit) were considered to be negative. ${ }^{\dagger}$ Serum from dam $\mathrm{l}_{90}-5$ was also tested at 100 days of gestation and was PRRSV-positive with a PRRSV titre of $2.6 \log 10 \mathrm{TCID}_{50} / \mathrm{mL}$. 

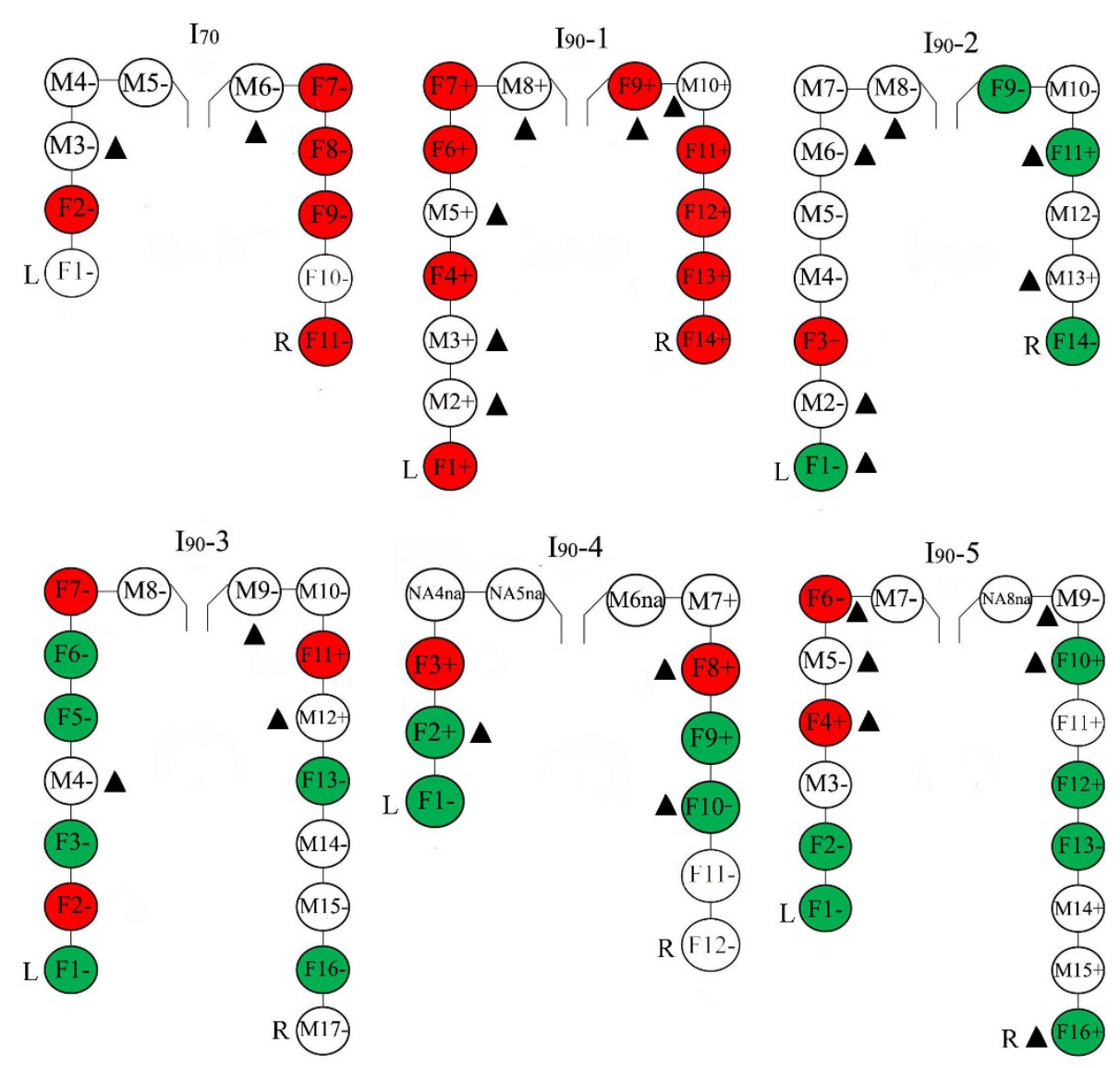

Con-1

Con-2

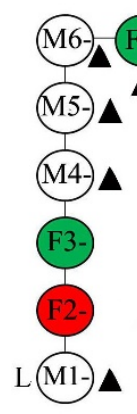

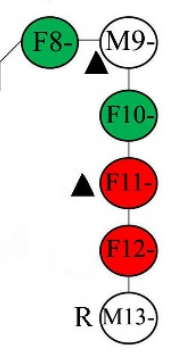

F10-

(M13-

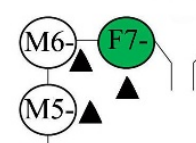

(F4.)

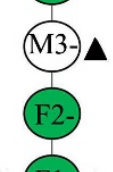

LF1-A

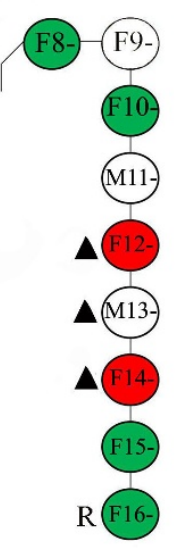

Con-3

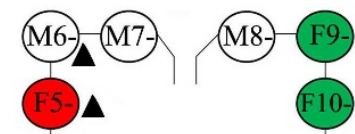

(M4)

(M11.)

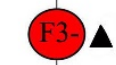

$\triangle(M 12$.

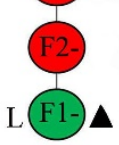

F13-

(M14.

R $\triangle$ M15.

Figure 1 Diagrams schematically represent the porcine uteri of the nine dams included in the study. Fetuses were numbered starting with the fetus located next to the ovarian tip of the left uterine horn. $L$ and $R$ : left and right uterine horn, respectively. Each circle represents an individual fetus. F: female and M: male fetuses. " + " and "-" within the circles represent PRRSV-positive and -negative fetuses. Filled circles are female fetuses that were tested for the presence of male sex-determining region Y (SRY) in serum via PCR. Red and green circles are SRYpositive or -negative fetuses, respectively. Female fetuses with non-filled circles were not tested due to the lack of serum $\mathbf{\Delta}$ : in these fetuses microchimeric cells were found. na: not available; due to mummification the determination of fetal gender and PRRSV infection status was not possible. 
Additional file 4). Female cells were found at higher numbers within organs of male fetuses versus the number of male cells within organs of female fetuses $(p<$ 0.05 , tested with the Mann-Whitney rank sum test). Representative images of microchimeric cells found in female and male samples are shown in Figure 2.

\section{Discussion}

To the authors' knowledge, this is the first report of porcine transplacental DNA and/or nucleated cell trafficking in healthy as well as in PRRSV-infected dams and their fetuses. Only in one recent study, released during the preparation of this manuscript, human cells injected into porcine fetuses were detected in unmanipulated siblings [29].

In the present study, female cells were observed within tissues of male fetuses. These cells can be of female sibling and/or maternal origin. Concurrent invasion from female siblings and mother is also possible. The observations that the number of male microchimeric fetuses is significantly higher than the number of female microchimeric fetuses and that the number of female microchimeric cells within male tissues is significantly higher than the number of male microchimeric cells within female tissues is in agreement with the scenario of a double origin (sibling and maternal). Since PRRSV replication in the fetal implantation sites is restricted to $\mathrm{Sn}+/ \mathrm{CD} 163+$ macrophages $[21,22]$ and as shown in the present study, porcine nucleated cells can migrate transplacentally, it is possible that PRRSV uses maternal susceptible macrophages as a vehicle to cross the uterine epithelium/trophoblast layers and reach fetal tissues. To further support this theory, the maternal/fetal origin of female macrophages within male fetuses should be demonstrated.
The present experimental design did not allow to type microchimeric cells and to distinguish maternal from female fetal cells.

Male DNA and cells within sera and organs of female fetuses are most probably of male sibling origin. Porcine fetuses have individual fetal membranes and starting from 39-55 days of gestation, large central placental zones of the individual conceptuses are terminated by two extremities of the fetal sacs which include paraplacental and ischemic zones (necrotic tips) [30]. During pregnancy, adherence seems to occur between adjacent extremities of the fetal sacs [30]. Fetal cells may migrate between siblings through these extremities. After invading the neighboring sibling, fetal cells can degrade and release DNA and/or survive and engraft into tissues. From 60 days of gestation there are different degrees of adherences between fetal sac extremities within the uterus [30]. This may explain the difference in number of SRY-positive female fetuses between dams and in number of microchimeric cells within fetuses from the same dam. Some female fetuses that did not have in utero contacts with male fetuses also had SRY in sera and microchimeric cells within their tissues (Figure 1, Additional file 2). It looks like cells may pass from a male fetus through adjacent female siblings to more distant female fetuses.

In a study of Lager et al., selected porcine fetuses were inoculated in utero with PRRSV [31]. Afterwards, the virus could be isolated from inoculated as well as noninoculated neighboring and more distant fetuses. It is very well possible that PRRSV is using sibling microchimeric cells to cross over the fetuses within the uterus. The proposed way of virus spread between mother and fetuses and in between siblings may not be only applied to PRRSV, but also to other porcine pathogens.
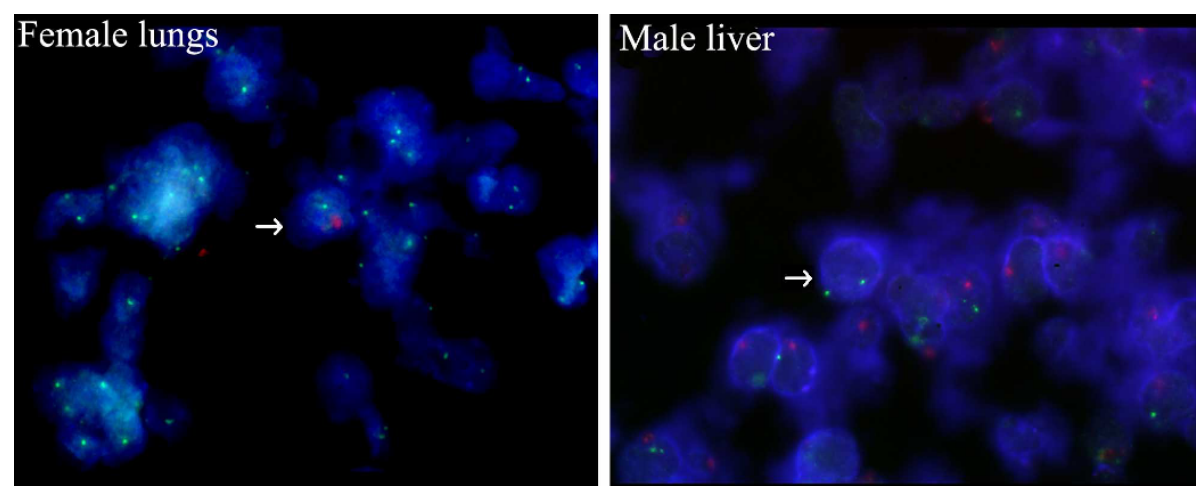

Figure 2 Microchimeric cells found in female and male samples. Red-dUTP and Green-dUTP (Abbott Molecular, USA) were used as fluorophores for the $Y$ and $X$ probes, respectively. FISH analysis on female lungs and male liver using probes for the $X$ (green signal) and $Y$ (red signal) chromosomes. Cell nuclei were counterstained with DAPI (blue). Arrows indicate microchimeric cells. FISH images of male and female cells were recorded using a Zeiss Axioplan 2 fluorescence microscope, a high-sensitivity integrated CCD camera and dedicated software (ISIS, MetaSystems, Germany). 
Interestingly, the percentage of PRRSV-positive animals was higher among female fetuses $(50 \%)$ than among male fetuses (33\%). This might suggest that the fetal gender is linked with the susceptibility of porcine fetuses to PRRSV infection. In line with this, previous observations in humans suggest that girls are at higher risk of in utero HIV infection than boys [32]. However, further research is necessary to determine if there is an actual direct connection between porcine fetal gender and susceptibility to PRRSV.

Microchimerism may benefit or compromise maternal and fetal health in humans [1,17-19]. Swine are recognized as a suitable animal model for human diseases based upon their comparative anatomy and physiology [33-35]. Further elaboration of microchimerism in swine will open new perspectives to design functional investigations to study the subject.

In the present study, it was demonstrated that PRRSV infection does not influence microchimerism. However, it is very well possible that PRRSV misuses maternal and sibling microchimeric cells during pregnancy to spread from mother to fetus and in between the fetuses. Further studies are needed to validate that maternal/fetal macrophages are spreading from dam to the fetuses and in between the fetuses, and that PRRSV misuses these cells to establish congenital infection.

\section{Additional material}

Additional file 1: SRY and ZFX PCR assay validation. During SRY and ZFX PCR assay validation, amplification products were subjected to gel electrophoresis to ensure the correct size of amplicons. SRY (amplicon size is 71 bp): (1) ladder; (2) fetal male serum DNA; (3 and 4) SRY-positive female fetal serum DNA; (5 and 6) SRY-positive dam serum DNA; (7) SRYnegative female fetal serum DNA; (8) SRY-negative dam serum DNA; (9) DNA from skin of male pig; (10) DNA from skin of female pig; (11) human serum DNA (a weak band of approximately 500 bp was observed in the human serum sample, but no positive signal was detected in the SRY real time PCR assay); (12) non template control. ZFX (amplicon size is 91 bp): (1) ladder; (2) male fetal serum DNA; (3) female fetal serum DNA; (4) dam serum DNA; (5) DNA form skin of male pig; (6) DNA from skin of female pig; (7) human serum DNA; (7) non template control.

\section{Additional file 2: Virological, PCR and FISH findings in female} fetuses.

Additional file 3: Virological, PCR and FISH findings in male fetuses. Additional file 4: The statistical analyses of FISH data

\footnotetext{
Acknowledgements

The authors acknowledge Dipongkor Saha, Lieselotte Pattyn, Marijke Van Den Wiele for their excellent technical assistance. The animal experiment was executed in full compliance with guidelines of the Ethical Committee of the Faculty of Veterinary Medicine, Ghent University. The research leading to these results has received funding from the European Union Seventh Framework Programme (FP7/2007-2013) under grant agreement $n^{\circ} 245141$. Uladzimir U Karniychuk was supported by B/10641/02-BOF09/DOC/032 grant from the special Research Fund of Ghent University.
}

\section{Author details}

'Laboratory of Virology, Faculty of Veterinary Medicine, Ghent University, Ghent, Belgium. ${ }^{2}$ Center for Medical Genetics, Ghent University Hospital, Ghent, Belgium. ${ }^{3}$ INRA, Laboratory of Animal Genetics and Integrative Biology, Jouy-en-Josas, France.

\section{Authors' contributions}

UUK conceived and designed the study, carried out PCR and participated in $\mathrm{FISH}$, performed the statistical treatment of data and drafted the manuscript. WVB participated in FISH and helped in writing the manuscript. NVR developed and adapted FISH. CRG produced probes for FISH. HJN coordinated the work and helped in writing the manuscript. All authors read and approved the final manuscript.

\section{Competing interests}

The authors declare that they have no competing interests.

Received: 15 July 2011 Accepted: 16 March 2012

Published: 16 March 2012

\section{References}

1. Gammill HS, Nelson JL: Naturally acquired microchimerism. Int I Dev Biol 2010, 54:531-543.

2. Peretti V, Ciotola F, Albarella S, Paciello O, Dario C, Barbieri V, lannuzzi L: XX/XY chimerism in cattle: clinical and cytogenetic studies. Sex Dev 2008, 2:24-30.

3. Marcum A: Chimerism in a bull calf. Hereditas 1974, 76:154-156.

4. van Dijk BA, Boomsma DI, de Man AJ: Blood group chimerism in human multiple births is not rare. Am J Med Genet 1996, 61:264-268.

5. Hall JM, Lingenfelter P, Adams SL, Lasser D, Hansen JA, Bean MA: Detection of maternal cells in human umbilical cord blood using fluorescence in situ hybridization. Blood 1995, 86:2829-2832.

6. Piotrowski P, Croy BA: Maternal cells are widely distributed in murine fetuses in utero. Biol Reprod 1996, 54:1103-1110

7. Lo YM, Lo ES, Watson N, Noakes L, Sargent IL, Thilaganathan B, Wainscoat JS: Two-way cell traffic between mother and fetus: biologic and clinical implications. Blood 1996, 88:4390-4395.

8. Petit T, Gluckman E, Carosella E, Brossard Y, Brison O, Soce G: A highly sensitive polymerase chain reaction method reveals the ubiquitous presence of maternal cells in human umbilical cord blood. Exp Hematol 1995, 23:1601-1605.

9. Petit T, Dommergues M, Socie G, Dumez Y, Gluckman E, Brison O: Detection of maternal cells in human fetal blood during the third trimester of pregnancy using allele-specific PCR amplification. $\mathrm{Br} J$ Haematol 1997, 100:767-771.

10. Lo ESF, Lo YMD, Hjelm NM, Thilaganathan B: Transfer of nucleated maternal cells into fetal circulation during the second trimester of pregnancy. Br J Haematol 1998, 100:605-606.

11. Nelson JL, Gillespie KM, Lambert NC, Stevens AM, Loubiere LS, Rutledge JC, Leisenring WM, Erickson TD, Yan Z, Mullarkey ME, Boespflug ND, Bingley PJ, Gale EA: Maternal microchimerism in peripheral blood in type 1 diabetes and pancreatic islet beta cell microchimerism. Proc Natl Acad Sci USA 2007, 104:1637-1642.

12. Schmorl G: Pathologisch-anatomische untersuchungen über puerperaleklampsie Leipzig: Verlag FCW Vogel; 1983.

13. Bromberg YM, Salzberger M, Abrahamov A: Transplacental transmission of fetal erythrocytes with demonstration of fetal hemoglobin in maternal circulation. Obstet Gynecol 1956, 7:672-674.

14. O'Donoghue K, Choolani M, Chan J, de la Fuente J, Kumar S, Campagnoli C, Bennett PR, Roberts IA, Fisk NM: Identification of fetal mesenchymal stem cells in maternal blood: implications for non-invasive prenatal diagnosis. Mol Hum Reprod 2003, 9:497-502.

15. Adams Waldorf KM, Gammill HS, Lucas J, Aydelotte TM, Leisenring WM, Lambert NC, Nelson JL: Dynamic changes in fetal microchimerism in maternal peripheral blood mononuclear cells, CD4+ and CD8+ cells in normal pregnancy. Placenta 2010, 31:589-594.

16. Ariga H, Ohto H, Busch MP, Imamura S, Watson R, Reed W, Lee TH: Kinetics of fetal cellular and cell-free DNA in the maternal circulation during and after pregnancy: implications for noninvasive prenatal diagnosis. Transfusion 2001, 41:1524-1530 
17. Ichinohe T: Long-term feto-maternal microchimerism revisited: Microchimerism and tolerance in hematopoietic stem cell transplantation. Chimerism 2010, 1:39-43.

18. Boyon C, Vinatier D: Fetal microchimerism: Self and non-self, finally who are us? J Gynecol Obstet Biol Reprod 2011, 40:387-398, (in French).

19. Kallenbach LR, Johnson KL, Bianchi DW: Fetal cell microchimerism and cancer: a nexus of reproduction, immunology, and tumor biology. Cancer Res 2011, 71:8-12.

20. Christianson WT, Choi CS, Collins JE, Molitor TW, Morrison RB, Joo HS: Pathogenesis of porcine reproductive and respiratory syndrome virus infection in mid-gestation sows and fetuses. Can J Vet Res 1993 57:262-268.

21. Karniychuk UU, Nauwynck HJ: Quantitative changes of sialoadhesin and CD163 positive macrophages in the implantation sites and organs of porcine embryos/fetuses during gestation. Placenta 2009, 30:497-500.

22. Karniychuk UU, Saha D, Geldhof M, Vanhee M, Cornillie P, Van den Broeck W, Hans J, Nauwynck HJ: Porcine reproductive and respiratory syndrome virus (PRRSV) causes apoptosis during its replication in fetal implantation sites. Microb Pathog 2011, 51:194-202.

23. Wienecke J, Hebel K, Hegel K, Pierau M, Brune T, Reinhold D, Pethe A, Brunner-Weinzierl MC: Pro-inflammatory effector Th cells transmigrate through anti-inflammatory environments into the murine fetus. Placenta 2012, 33:39-46.

24. Karniychuk UU, Geldhof M, Vanhee M, Van Doorsselaere J, Saveleva TA, Nauwynck HJ: Pathogenesis and antigenic characterization of a new East European subtype 3 porcine reproductive and respiratory syndrome virus isolate. BMC Vet Res 2010, 6:30.

25. Rogel-Gaillard C, Bourgeaux N, Billault A, Vaiman M, Chardon P: Construction of a swine BAC library: application to the characterization and mapping of porcine type $\mathrm{C}$ endoviral elements. Cytogenet Cell Genet 1999, 85:205-211.

26. Van Roy N, Laureys G, Cheng NC, Willem P, Opdenakker G, Versteeg R Speleman F: 1;17 translocations and other chromosome 17 rearrangements in human primary neuroblastoma tumors and cell lines. Genes Chromosomes Cancer 1994, 10:103-114.

27. Van Limbergen H, Poppe B, Michaux L, Herens C, Brown J, Noens L, Berneman Z, De Bock R, De Paepe A, Speleman F: Identification of cytogenetic subclasses and recurring chromosomal aberrations in AML and MDS with complex karyotypes using M-FISH. Genes Chromosomes Cancer 2002, 33:60-72.

28. Pomp D, Good BA, Geisert RD, Corbin CJ, Conley AJ: Sex identification in mammals with polymerase chain reaction and its use to examine sex effects on diameter of day-10 or-11 pig embryos. J Anim Sci 1995, 73:1408-1415.

29. McConico A, Butters K, Lien K, Knudsen B, Wu X, Platt JL, Ogle BM: In utero cell transfer between porcine littermates. Reprod Fertil Dev 2011, 23:297-302.

30. Ashdown RR, Marrable AW: Adherence and fusion between the extremities of adjacent embryonic sacs in the pig. J Anat 1967, 101:269-275.

31. Lager KM, Mengeling WL: Pathogenesis of in utero infection in porcine fetuses with porcine reproductive and respiratory syndrome virus. Can J Vet Res 1995, 59:187-192.

32. Biggar RJ, Taha TE, Hoover DR, Yellin F, Kumwenda N, Broadhead R: Higher in utero and perinatal HIV infection risk in girls than boys. J Acquir Immune Defic Syndr 2006, 41:509-513.

33. Meurens F, Summerfield A, Nauwynck H, Saif L, Gerdts V: The pig: a model for human infectious diseases. Trends Microbiol 2012, 20:50-57.

34. Dynarowicz I, Mortensen A, Watkowski T: The role of adrenergic receptors in the regulation of blood flow in the reproductive organs of swine during the estrous cycle. Pol Arch Weter 1988, 28:115-127, (in Polish).

35. Scharl A, Beckmann MW, Artwohl JE, Holt JA: Comparisons of radioiodoestradiol blood-tissue exchange after intravenous or intraarterial injection. Int J Radiat Oncol Biol Phys 1995, 32:137-146.

doi:10.1186/1297-9716-43-19

Cite this article as: Karniychuk et al:: Demonstration of microchimerism in pregnant sows and effects of congenital PRRSV infection. Veterinary Research 2012 43:19.

\section{Submit your next manuscript to BioMed Central and take full advantage of:}

- Convenient online submission

- Thorough peer review

- No space constraints or color figure charges

- Immediate publication on acceptance

- Inclusion in PubMed, CAS, Scopus and Google Scholar

- Research which is freely available for redistribution

Submit your manuscript at www.biomedcentral.com/submit 